\title{
Reivindicación católica de una danza: pistas para interpretar a los Tlahualiles de Sahuayo, Michoacán
}

\section{Catholic vindication of a dance: Approaches for interpreting the Tlahualiles of Sahuayo, Michoacan}

\author{
IVY JACARANDA JASSO MARTÍNEZ* \\ Alejandro Martínez De la Rosa ${ }^{\star *}$ \\ doi) doi.org/10.29043/liminar.v20i2.906
}

Resumen: El objetivo de este trabajo es presentar una reflexión general de la danza de Tlahualiles que se practica en Sahuayo (Michoacán, México) y proponer una interpretación de su significado tomando en cuenta su dinámica actual. Exponemos dos visiones, una interpretación a partir de material documental histórico y una descripción de la danza desde los mismos participantes, para mostrar las dinámicas internas y las posibles tensiones entre sus orígenes y su actualidad. La tensión entre religiosidad católica y religiosidad popular parece estar presente en la práctica de esta danza. En este sentido, registramos un reciente proceso de "consagración" para eliminar elementos "paganos" que habían imperado. La metodología consistió en el análisis de material documental histórico y una aproximación cualitativa con las siguientes técnicas: entrevistas, charlas informales y la observación de la danza en diferentes espacios.

Palabras clave: danza tradicional, danza de Tlahualiles, fiestas religiosas, religiosidad popular.

Abstract: The objective of this article is to present a general reflection regarding the dance of the Tlahualiles performed in Sahuayo (Michoacan, Mexico) and to propose an interpretation of its meaning taking into account its current dynamics. We present two visions (an interpretation of historical documentary material and a description of the dance by its participants) to show the internal dynamics and possible tensions between its origins and its current state. The tension between Catholic religiosity and popular religiosity appears to be present in the performance of this dance. We registered a recent process of "consecration" to eliminate "pagan" elements that had prevailed. Our methodology consisted of analyzing historical documentary material and a qualitative approach involving techniques that included interviews, informal talks, and the observation of the dance at different venues.

Key words: traditional dance, dance of the Tlahualiles, religious celebrations, popular religiosity.

* Departamento de Estudios Sociales, Campus. León, Universidad de Guanajuato, México

** Departamento de Estudios Culturales, Campus León, Universidad de Guanajuato, México amdelarosa@ugto.mx 


\section{Introducción}

$\mathrm{E}$ n el año 2016 visitamos la cabecera municipal de Sahuayo, en el estado de Michoacán (México), para reunirnos con la mesa directiva de los grupos de danzantes de Tlahualiles. En esa ocasión pudimos conocer a sus integrantes y sus opiniones, además identificamos las diferentes etapas y procesos que ocurren durante las festividades del santo patrono del lugar, Santiago Apóstol, cuando aproximadamente 135 grupos de danza realizan sus recorridos por las calles de la localidad para conmemorarlo. Los números son muestra de que esta danza se ha extendido y actualmente involucra a toda la comunidad. Desde la década de los ochenta del siglo XX las danzas de Tlahualiles se han organizado en agrupaciones; en el año 2006 se conformaron tres asociaciones civiles de danzantes, y la mesa directiva incluyó a la gran mayoría de los grupos con el interés de preservar dicha danza. ${ }^{1}$

La danza de Tlahualiles al parecer no tiene relación con otras de la región, incluso no aparece en otras localidades del municipio, pero los danzantes expresan un orgullo en su escenificación. Es posible encontrar alguna similitud con danzas de conquista, que se caracterizan por "La formación de dos grupos cuyo antagonismo se fundamenta - por medio de la escenificación de un combate - en la conquista, recuperación o defensa de un territorio" (Bonfiglioli y Jáuregui, 1996, p. 12), y de acuerdo con las representaciones, parece tener algún sustrato semejante con la de Santiago —en la que se enfrentan dos bandos: moros-aztecas y cristianos-charros- y con la danza del caballito blanco, que exhibe la confrontación bélica entre españoles e indígenas (Bonfiglioli y Jáuregui, 1996). Si bien en la mayor parte de la escenificación no existen bandos, en los momentos clave de la celebración hacen presencia las "Mulitas" o Santiagos montados en sus caballos como contraparte de los Tlahualiles.

El objetivo de este texto es presentar una reflexión general sobre la danza y proponer una interpretación de su significado. Exponemos dos visiones: una interpretación a partir de la presentación de material documental histórico y una descripción de la danza desde los mismos participantes, para mostrar las dinámicas internas y posibles tensiones entre sus orígenes y su modalidad actual. Consideramos que estas dos visiones se articulan y entran en diálogo.

Como parte del proyecto "El complejo genérico de matachines y sus prácticas identitarias en diversas regiones culturales de México y el sur de Estados Unidos"2 nos propusimos una aproximación cualitativa que permitiera conocer las opiniones y sentires de los danzantes de Tlahualiles en Sahuayo. A partir de las visitas a esta ciudad pudimos dialogar con responsables de grupos de danza, integrantes de la mesa directiva y personas que se dedican a la confección de diferentes elementos del vestuario. Se realizaron entrevistas y charlas informales, y se observó la danza en diferentes espacios. Además se llevó a cabo la búsqueda de material documental que ayudara a determinar su significado o la referencia del nombre de la danza. En este sentido, fue posible conocer las relaciones y los diferentes intereses y motivaciones a partir de la ejecución de la danza, así como plantear una hipótesis interpretativa general, la cual exponemos en el presente texto.

\footnotetext{
${ }^{1}$ Este texto fue posible gracias al financiamiento PRODEP-SEP conferido al proyecto "El complejo genérico de matachines y sus prácticas identitarias en diversas regiones culturales de México y el sur de Estados Unidos". Además agradecemos sinceramente a la Mesa Directiva de Tlahualiles 2016 por su apoyo y confianza para realizar este trabajo de documentación de su danza.

${ }^{2}$ Proyecto elaborado por la Red temática “Identidades y diversidades kinético-sonoras", financiado por PRODEP-SEP en colaboración con el Cuerpo Académico Etnocoreología y Etnomusicología de la Benemérita Universidad Autónoma de Puebla, México.
} 


\section{Apuntes sobre religiosidad popular}

Una manera de abordar el análisis del contexto de la danza es desde los trabajos enmarcados en la perspectiva de la religiosidad popular. Una de sus primeras premisas al tratar este análisis es desechar la lógica de opuestos o en franca oposición entre la religiosidad oficial y la popular; si bien se enuncia una autonomía de esta sobre las instituciones eclesiales - como proceso paralelo a la religión oficial según Gómez Arzápalo (2019) - , se afirma que se encuentran en tensión y negociación, y que en algunas ocasiones se toleran, se aceptan, coinciden, se complementan y pueden llegar a consensos y acomodos (Báez-Jorge, 1996; Gómez A., 2009). En esta línea, De la Torre afirma que la religiosidad popular permite indagar los "espacios intermedios entre diferentes zonas de influencia entre lo individual y lo institucional, entre lo nuevo y lo tradicional [...] entre los sincretismos coloniales y los hibridismos poscoloniales", permitiendo analizar las continuidades con la tradición (De la Torre, 2013, p. 7).

Otro aspecto relevante es el cruce entre las religiones (Giménez en Gómez A., 2009), y el sincretismo (Landázuri, 2012) que "expresa articulaciones y contradicciones históricamente configuradas" (BáezJorge, 1996, p. 8). El mensaje cristiano "se reformuló traduciéndose a un lenguaje entendible, coherente y significativo de acuerdo con el horizonte de sentido propio de las culturas indígenas que - de esta forma - se apropiaron del cristianismo desde su propio proceso selectivo y dinámico" (Gómez A., 2019, p. 228). Pero no se trata solo de una yuxtaposición entre diversas culturas, refiere más precisamente a una "matriz generativa entre marcos de creencias diversas" (De la Torre, 2013, p. 7). Esto implica una cualidad creativa que integra "la imaginación popular y los valores de la cultura ancestral reelaborados simbólicamente” (Báez-Jorge, 1996, p. 7).

Lo anterior se vincula con otra de las características de la religiosidad popular al ser definida a partir de su vivacidad y su constante redefinición y recreación. La religión popular no es estática, no se configura de una vez y para siempre, por el contrario, se caracteriza por su dinamismo: "entre la asimilación y el rechazo a la modernidad, entre la resistencia cultural de las tradiciones y su respuesta no sólo adaptativa, sino también perfomativa para encarar y generar vías alternas [de] ser y estar en la modernización contemporánea" (De la Torre, 2013, p. 7).

Otro de los aspectos que enuncian quienes estudian el tema se refiere al vínculo que se establece entre los aspectos-procesos religiosos y los económicos, políticos y sociales en la comunidad; es decir, la religiosidad popular puede dar cuenta de la organización económica y política que caracteriza a la población (Gómez A., 2009; Landázuri, 2012). Al implicar esfuerzos colectivos, su práctica evidencia los arreglos y tensiones que ocurren en el interior del grupo y con otros grupos o sociedades.

Giménez (en Gómez A., 2009) menciona además la relación marcada entre estratos populares marginados y la religiosidad popular que, si bien se puede ubicar entre las sociedades indígenas y campesinas, también se identifica en las urbes.

Finalmente, Gómez A. (2009) menciona las siguientes claves estructurales de la religiosidad popular: las imágenes de santos, los santuarios y peregrinaciones, y los sistemas de cargos. Estos elementos confieren matices importantes en cada expresión situada de la religiosidad popular y posibilitan materialmente la vida ritual. Trataremos estas claves en cada apartado para generar una reflexión amplia sobre su pertinencia en el caso de la danza de Tlahualiles y su celebración en honor a Santiago Apóstol. 


\section{El contexto: Sahuayo, Michoacán}

El municipio de Sahuayo se localiza en la parte noroeste del estado de Michoacán, cerca del lago de Chapala, en el estado de Jalisco, México (Municipios.mx, s. f.). El término "sahuayo" procede del náhuatl y tiene diferentes interpretaciones: "en donde da la sarna" o "vasija que tiene el aspecto de una tortuga” (INAFED, 2017). Según la historia local, la comunidad se fundó en el año 1530, y se cree que los primeros habitantes de esta región fueron aztecas, quienes después fueron sometidos por el Imperio tarasco. La conquista espiritual estuvo a cargo de la orden de San Francisco, encabezados por fray Juan de Badía (INAFED, 2017).

La población participó en el movimiento revolucionario de forma tardía, y tuvo una intervención muy activa en la llamada guerra cristera. Con el gobierno de Lázaro Cárdenas del Río, y una vez que la cristiada se disolvió, se repartió parte de la hacienda a campesinos de Sahuayo (INAFED, 2017).

La principal festividad se realiza en honor del santo patrono Santiago Apóstol, aunque también se celebra a la virgen de Guadalupe y al niño beato José Sánchez del Río (10 de febrero), quien pertenecía a las fuerzas cristeras y fue hecho prisionero y torturado para que renegara de la fe católica. Sahuayo es una ciudad conocida en la región por la fabricación de huaraches y sombreros - posiblemente oficio heredado de los arrieros y artesanos de antaño-, aunque también se reconocía a la comunidad por la agricultura y el comercio.

\section{Indicios de los Tlahualiles: hacia una interpretación de la danza}

En cuanto al significado de la palabra náhuatl tlahualil, encontramos en la localidad dos sentidos: "guerrero vencido" y "revestirse para la fiesta", siendo la segunda definición la más actual, aunque se evidencia que los habitantes desconocen el significado a ciencia cierta.

Hernández y Canuto (2019) afirmaron no haber encontrado relación con alguna palabra en náhuatl en los vocabularios, como en el de Molina (1571); sin embargo, nos parece que el término tlahualil podría relacionarse con uno usado actualmente en otras latitudes. En el Diccionario del náhuatl en el español de México solo aparece una referencia cercana en las toponimias: en el estado de Durango existe el municipio llamado Tlahualilo, homónimo de la cabecera también, aunque se define como forma pasiva de alumbrar: tlahuilia, por lo cual tlahualilo significaría "donde la gente es alumbrada”. Esta acepción no tendría relación semántica con nuestro tema pues este significado refiere a una pronunciación relacionada con tlahuililo (Montemayor, 2017, p. 262). Incluso en el propio municipio se define el concepto a partir de las raíces tlalli, "tierra fértil", y ahualila, "agua para regadío" (INAFED, ca. 2013).

$\mathrm{Al}$ seguir esta infructuosa definición, pensamos que el término de nuestro interés proviene de otra raíz, no de tlahuilia, sino de tlauele, ya que no se encontró alguna palabra específica para la raíz tlahual. Tlauele significa "furioso, iracundo, exaltado, violento", y tlaueliloc "malvado, perverso" (Simèon, 2014, pp. 689-690), y en el Vocabulario en lengua castellana y mexicana de Alonso de Molina tlauele significa sañudo, iracundo y bravo, y tlaueliloc malvado o bellaco (Molina, 1571, p. 144).

A partir de estas referencias aisladas y de los relatos de los primeros cronistas se podría ubicar su uso contextual; en este sentido, nos referiremos a la obra de Bernardino de Sahagún, quien diferenciaba dos tipos de naoalli: aquel que "es curioso deste oficio" y "no daña", y el que es "maléfico y pestífero deste 
oficio, hace daño á los cuerpos con los dichos hechizos, saca de juicio y ahora, es evaydor, ó encantador", según la versión en español (Sahagún, 1830, p. 22); en la versión en náhuatl usa los términos "qualli naoalli" y "tlahueliloc naoalli", respectivamente.

Sin embargo, algunos investigadores ponen en duda la traducción sesgada del fraile, pues en este capítulo se distinguen dos tipos de astrólogos: el hábil y el inhábil nigromántico, según la traducción en español, pero en la versión en náhuatl se contrasta entre el conocedor de los libros y de la cuenta de los días, y el hechicero embustero. El contraste fue el resultado de contraponer las traducciones de las frases "In tlapouhqui ca tlamatini" e "In tlaueliloc tlacateculotl" (Martínez, 2018, pp. 38-40). Aquí la traducción del término tlahueliloc resulta equívoca de un párrafo a otro: se habla de una persona maléfica y pestífera, pero también inhábil.

Acerca de dicha distinción entre hábiles e inhábiles, Miguel León Portilla adjudicó a los primeros el papel de "sabios nahuas" (tlamatinime), y a los segundos el de "falso médico, brujo o nahual, burlador de la gente". Con esto volvemos a observar una distancia entre maléfico, inhábil y falso. Más bien traduce la idea general de manera más certera en la frase siguiente: "uno era el saber basado en el conocimiento y el método y otro el de la magia y hechicerías” (León, 1997, pp. 63-88). Esta última inferencia se verá más adelante con el análisis de la relación de los términos tlacatecolotl y tlahueliloc entre los actuales hablantes de náhuatl en la Huasteca.

Otra acepción interesante de tlahueliloc es la de "animal montaraz" o "no humano", relacionada con el difrasismo "ser conejo, ser venado":

"Volverse conejo, volverse venado" era adquirir características bestiales, reflejadas en el no cumplimiento de los mandatos paternos y de la sociedad en general. Es el que no escuchaba consejo, que andaba de un lugar a otro sin asentarse, tal como lo hacen los animales montaraces; era salirse de lo establecido. De esta manera, el tlahueliloc corresponde al loco moral, el que violaba las normas del buen comportamiento irrumpiendo el equilibrio social y cósmico.

[...] De igual manera, el que enloquecía por acción de las cihuapipiltin se le denominaba tlahueliloc (Echeverría, 2005, pp. 58-60).

Ante estas acepciones, el término se plantea como un tipo de locura, pero también se asume como un comportamiento desequilibrado, fuera de lo establecido. La complejidad aumenta si se revisan otros tipos de locura definidos con los términos: chicotlahueliloc (loco atreguado), cuautlahueliloc (malvado de la cabeza), yollotlahueliloc (malvado del corazón). A tales referencias lingüístico-históricas se suman los usos del término en la actualidad.

En las fiestas de carnaval en comunidades nahuas del municipio de Ixhuatlán de Madero, Veracruz, aparece un personaje que nombran Tlahuelilo, por ejemplo en Tlachiquile:

Se acostumbra iniciar la festividad carnavalesca con una ceremonia nocturna en la que se levanta una efigie [un enorme muñeco relleno de hojas] sobre un altar ceremonial en forma de tarima (tlapextle) en dos niveles. Esta figura es la representación de Tlacatecólotl, "hombre búho", divinidad temida por su conducta voluble, también reconocido como Tlahuelilo, el "diablo", a quien se le dedica la fiesta y es tributado por un periodo de cuatro días con danzas, música, velas, comida, bebida y dinero. Al concluir la fiesta esta imagen de la deidad es conducida en procesión y con honores hasta las afueras 
del pueblo; los disfrazados le agradecen por haberles prestado su espíritu y su fuerza durante los días de Carnaval, al tiempo que participan en un ritual de limpia con intenciones purificatorias. Después el tiempo se encargará de destruir la imagen de la deidad venerada (Croda, 2009, p. 157).

A partir de esta cita podemos relacionar a los tlahualiles o tlahuelilos con una danza de "diablos"; así, los tlahualiles sahuayenses serían la unificación significativa de la efigie y los disfrazados que participan en un ritual de purificación, porque la única imagen, deidad o "muñeco" que aparece en Sahuayo durante las fiestas es el propio Santiago. La conducta voluble y temida de Tlacatecolotl coincide con el significado de iracundo y bravo del término tlauele; a su vez, la acepción de bellaco y malvado tendría por personaje típico al diablo, a la manera cristiana.

González comenta que en algunas comunidades Tlacatecolotl y Tlauelilo ("el iracundo") son el mismo personaje, mientras en otras no; apunta que en la Huasteca meridional, en el estado de Hidalgo, se celebra una semana antes del Miércoles de Ceniza el nanauatili o carnaval, donde se ofrece a "los señores de la oscuridad", "entes que si bien están asociados a la brujería y a la etiología, también ayudan a la fortuna y a conseguir dinero"; en estas fiestas Tlacatecolotl se hace acompañar de varios diablos (González, 2009, p. 232). Al día siguiente se lleva a cabo la danza de mecos:

La comparsa de mekomej son la presencia de almas en pena que han tomado por la vía de las máscaras a pobladores jóvenes. Danzarán de forma circular (levógira) por todo el poblado [...]. En comunidades cercanas, como Ahuatitla, en Huejutla de Reyes, y en el municipio de Calnali, Hidalgo, no es extraño que "comanches" emerjan entre los danzantes, seres que portando máscaras con furia manifiesta, tocado de plumas, calzoncillo, arco y flechas, azotan a todo aquel que encuentran a su paso (González, 2009, pp. 233-234).

En esta representación los danzantes no son diablos pensados a la manera católica, sino muertos penando. Incluso en Chicontepec, Veracruz, al carnaval o nahnahuatili se le conoce igualmente como "mecohtiliztli o fiesta de los mecos", lo que demuestra la importancia de estos personajes, indios chichimecos, salvajes, iracundos y bravíos, que están imbuidos del tonal de Tlacatecolotl, y acompañan a las deidades oscuras del inframundo. ¿ No acaso los tlahualiles representan a indios no catequizados que bailan con bravura y pelean en contra de Santiago?

En la cotidianeidad los nahuas expresan el carácter dual de Tlacatecolotl, asociándolo al Demonio. Es imaginado ambivalente, indistintamente como hombre o mujer, anciano o niño, Señor de la Noche o Señor del Día. Dicen que, a la vez puede ser bueno y malo; que cura y embruja; da la vida y propicia la muerte; otorga y quita la riqueza; es muy voluble, "puede estar contento o enojado", razón por la cual "se le alegra" con danzas, música, comidas y cohetes. En el plano imaginario de su asociación satánica, hablan de Tlacatecolotl como Masehualdiablo ("diablo indígena") y de Coyodiablo (“diablo mestizo") o Tecocolihketl ("envidioso") entidad maligna que "odia a los indígenas", asusta en los caminos, "destruye las milpas" asumiendo la forma de toro. Se dice que es el patrono de los mestizos. También se le conoce como Tlahueliloc (Maligno). Lo describen alto y de color rojo, con cuernos y cola, "porta trinche" (tridente) y vive en el infierno comiendo lumbre. Desde luego, esta descripción corresponde a la imagen del Diablo que los catequistas difunden de manera insistente. 
[...] Los Tetlahchihuianeh (hechiceros) piden la ayuda a Tlacatecolotl para castigar o provocarle mal a alguien. Le rezan a la advocación Tlahueliloc ("malo, enfurecido"), ofreciéndole papel ceremonial manufacturado con fibras de ortigas y cornezuelos; comidas, bebidas, velas, copal y sangre de aves negras y rojas (Gómez M., 2009, pp. 276-289).

En el texto anterior parece que Tlacatecolotl es tratado como un agente indígena o de origen prehispánico, que conserva la dualidad de su carácter, mientras Tlahueliloc sería una advocación más mestiza y cercana a la iconografía católica del diablo, proceso este último que proviene del siglo XVI y se encuentra documentado en el Tratado de las hechicerías y sortilegios (1553), de fray Andrés de Olmos: "Vosotros habéis de saber que este hombre-búho (Tlacatecolotl) se llama verdaderamente por una multitud de nombres: mal ángel Diablo, Demonio, Sathán”, y después fue retomado por Torquemada (Báez-Jorge y Gómez, 1998, pp. 58-60). No obstante, ambos términos unificados están presentes en el universo mitológico concebido por los nahuas de Chicontepec, en la quinta y última capa del Mictlah (inframundo), denominada Mihcapantli, “ahí están Mikistli o Mikilistli (Señor de los Muertos) y Tlacatecolotl Tlahueliloc (hombre búho enfurecido)” (Báez-Jorge y Gómez, 1998, pp. 19-23).

Si bien geográficamente están muy alejadas la huasteca veracruzana y la hidalguense de la ciénega michoacana, y el carnaval no tendría que ver con una celebración relacionada con Santiago, el establecimiento de un sistema de creencias de índole popular reivindica el papel de aquellos indios bravos conocedores de las artes antiguas de sus antepasados remotos, en contraste con la versión hegemónica. A este respecto, Román, un párroco que estuvo en el lugar, afirma que Tlahualiles es como llamaron "los españoles a los nativos plebeyos que luchaban contra quienes a Santiago representaban en las fiestas moriscas después de la conquista tanto militar como espiritual” (Román, 1998, p. 120).

Pasemos ahora a describir la danza y algunos aspectos que le dan significado en su representación para relacionar estas pistas con su desarrollo en la época actual.

\section{La danza de Tlahualiles}

La danza de Tlahualiles, como la mayoría de las que existen en territorio mexicano y en buena parte de América Latina, es una combinación de un corpus de fiestas transferido desde Europa y divulgado en América, y de un corpus aborigen que en la actualidad es difícil de precisar con exactitud (Bonfiglioli y Jáuregui, 1996).

Al realizar una búsqueda de material bibliográfico acerca de esta danza reconocimos que es mínimo. El texto de José Trinidad Román Garza es la principal fuente de información. Román (1998) menciona que, en las fiestas religiosas de Sahuayo, organizadas por los frailes, se pusieron en práctica "las MORISMAS que solo son representaciones de las luchas que, supuestamente, sostuvo el Apóstol [Santiago] contra los moros cuando éstos ocupaban la Península Ibérica [...] Generalmente estos morismas, fiestas religiosas profanas, terminaban con el triunfo del cristianismo y la victoria de la cruz sobre la falsa idolatría" (Román, 1998, pp. 118-119). Esta mención indica que, además de la representación de una confrontación del santo local contra los idólatras, se trataba de fiestas religiosas profanas, lo que revela una posible escisión de esta práctica con el sistema eclesial católico.

Como se ha documentado, Santiago cruzó el Atlántico junto con los españoles, pero fueron las órdenes religiosas, en su papel evangelizador, las que al dar a conocer la religiosidad castellana a los indios 
desarrollaron su culto - especialmente los franciscanos, dominicos y agustinos- (Campos y Cardaillac, 2007, p. 17). Este santo, que había adquirido un marcado cuño militar, "tuvo solo el parangón de los enclaves consagrados a la virgen María. Y con unos atributos igualmente insistentes: Santiago Mataindios fue el nombre más que significativo, que se le impuso muchas veces, en evidente sintonía con el de Santiago Matamoros predecesor" (Pedrosa, 2013, pp. 15-16).

La danza de Tlahualiles se presenta como una práctica ritual en honor del santo Santiago. Para quienes han estudiado las danzas vinculadas con este santo se trata de una de las expresiones más importantes de religiosidad popular en México. Con estas danzas se "expresa una visión de la conquista, y de la actuación tanto de los vencedores como de los vencidos, que se ha forjado a través de los siglos" (Campos y Cardaillac, 2007, p. 69). A partir de la danza, los conquistadores mostraban las victorias del cristianismo sobre sus enemigos, pero con la reinterpretación que realizaron las sociedades indígenas de una práctica que les era familiar (danzar a los dioses) se desarrollaron variantes en casi todo el territorio del país (Campos y Cardaillac, 2007).

Lo anterior denota la incorporación de prácticas que se reinterpretan desde referentes propios; algunas variantes aparecen como la reivindicación de una identidad más profunda, mientras otras permiten a los participantes soñar su propia fuerza hasta apropiarse de la fuerza de los vencedores (Campos y Cardaillac, 2007). En este sentido, las diferentes interpretaciones que propusimos en el apartado anterior tienen cabida; cada población reinterpretó y ha podido refuncionalizar estos ritos de acuerdo con sus necesidades, moviéndose entre los matices existentes de la dicotomía sagrado/profano.

Las fiestas en honor a Santiago Apóstol transcurren del 16 al 25 de julio (dos novenarios) y del 25 de julio al 4 de agosto. En estas fechas se realizan recorridos en los que los Tlahualiles acompañan danzando a la imagen de Santiago Apóstol por las principales calles de la ciudad, y además llevan a cabo una escenificación en la que Santiago se enfrenta a los Tlahualiles, conocida como la Matanza: "es una representación de la batalla de Santiago en la conquista espiritual, este personaje se enfrenta con un tlahualil que se asemejan a los moros" (entrevista a Martín González, Sahuayo, 2016). Román menciona sobre la Matanza:

Se trataba de un ritual pagano religioso que tenía lugar el día 25 de julio a las 12 horas en la calle lateral sur del Santuario de Guadalupe [...] generalmente los Tlahualiles se reunían en "LA CRUZ" lugar donde, en la actualidad, está erigido el monumento a Cristo rey; poco antes del medio día bajaban del cerro, los guerreros enmascarados, hasta la calle ya señalada formando vayas [sic] para que pasara el Santiago Apóstol. Con la sola presencia de la imagen caían fulminados los supuestos enemigos, dos veces subía, dos veces bajaba, dos veces vencía de muerte a los aguerridos combatientes después de lo cual, los Tlahualiles, se diseminaban por toda la población hasta que, por la tarde, acompañaban en su peregrinar a la Sagrada Imagen, peregrinar que culminaba en LA CAPILLA hecha ex profeso en el conocido y popular barrio del Pedregal (Román, 1998, pp. 119-120).

En la actualidad esta confrontación, que se escenifica en el parque central, da cuenta de bandos opuestos y el triunfo siempre corresponde a Santiago; sin embargo, esta dicotomía puede no ser tan patente para las personas externas a la localidad, ya que durante los amplios recorridos que realizan los grupos de danza por las calles casi no hay enfrentamientos. Campos y Cardaillac (2007) afirman que, a diferencia de las versiones españolas de la danza, el protagonismo de Santiago vino a ser esencial en las versiones americanas. 
La Matanza o la escenificación de la confrontación continúa llevándose a cabo el día 25 de julio, y más recientemente se ha sumado otra fecha, el 2 de agosto. Puede durar entre doce y catorce horas debido al alto número de grupos participantes, donde los Santiagos son llamados irónicamente "Mulitas". Esto puede relacionarse con algunas de las variantes en las que ocurrían y ocurren comprensiones alternativas, según las cuales se ironiza, humilla o vence a Santiago (Campos y Cardaillac, 2007).

Anteriormente los recorridos se realizaban el 25 y 30 de julio y el 4 de agosto, pero en los últimos años son seis los días en que se danza - 16, 25, 28 y 30 de julio, y 2 y 4 de agosto-, es decir, se han sumado tres días más. Además se realizan recorridos breves en los que solo participan uno o dos grupos de Tlahualiles, como en las velaciones o para acompañar a un santo que va de visita. Específicamente se ha decidido que los días 24 y 25 de cada mes un grupo acompañará al santo Santiago Apóstol en su visita por las casas sin que sea obligatorio portar el traje, sino solo en representación. Esta ampliación de la práctica ritual podría sugerir un ajuste producto de las necesidades y demandas de la población (Gómez A., 2009) sin que necesariamente medien las instituciones católicas dominantes o se les pida consejo, lo que contribuye así a la "recreación de sentido desde la experiencia comunitaria" (De la Torre, 2013, p. 5).

El recorrido que realizan los Tlahualiles parece una procesión en la que se exhibe un desplazamiento hacia el centro religioso; desde la concepción de Gómez, esto ayuda a "delimitar el espacio sagrado, pero al mismo tiempo a expandir el espacio propio del pueblo, entendiendo éste como el campo de acción donde pueden ser ellos mismos" (Gómez A., 2009, p. 26). Esta clave de la religiosidad popular afianza y reafirma la propiedad comunitaria y la identidad (Gómez A., 2009).

\section{Vestuario}

El vestuario y el tocado son dos de las principales características de esta danza; especialmente el tocado, máscara o "penacho" que llevan en la cabeza, el cual es de grandes proporciones - entre 1.80 y 2 metros de altura - y tiene un peso aproximado de veinte a veinticinco kilos; está adornado por ambas caras con plumas de diferentes aves, diamantina y espejos, entre otros materiales, y su costo oscilaba en el año 2016 entre los cinco mil y los veinte mil pesos.

El señor Javier Guerrero comentó que, anteriormente, en el vestuario se utilizaban elementos de la naturaleza como pencas de nopal y plumas de aves de corral, los danzantes se pintaban la cara con tizne y se utilizaba carrizo. En esta línea, Hernández y Canuto retoman a Doyle para afirmar que, de acuerdo con fuentes iconográficas, en el año 1922 los Tlahualiles utilizaban una máscara "a la cual agregaban un bonete de cartón adornado con tiras de papel china y collares de tunas” (Doyle en Hernández y Canuto, 2019, pp. 12). Por su parte, Román comenta que en la década de 1940 los grupos de Tlahualiles eran escasos y más bien participaban solo individuos; en aquel entonces se formaron dos grupos: Matachines y Moros. El atuendo de los Matachines era el siguiente:

[...] daba la impresión de ser vestimenta árabe; no utilizaban machete, mazo o cualquier tipo de arma sólo una sonaja [...] El otro grupo, el de los "Moros" [...] tampoco usaba máscara pero su vestimenta era muy parecida a la que usaban los musulmanes; una característica muy especial es que salían montados a caballo, iban armados con descomunal machete y se hacían acompañar de individuos cuyo rostro era pintado con tintes negros con los que daban a entender su calidad de esclavos (Román, 1998, p. 121). 
Además de indicar la vestimenta de los grupos, esta información puede sugerir una relación con el sistema de danzas llamadas de matachines o matlachines. Sin embargo hay poco material para explorar de forma más amplia esta relación. Lo cierto es que se han presentado diversas modificaciones en el atuendo, que inició con trajes sencillos, hasta llegar a la compleja parafernalia que se utiliza en la época reciente. Lo que sí está documentado es que en la década de 1960 se registra ya el uso de máscaras y de trajes adornados (Hernández y Canuto, 2019; Román, 1998).

Lo anterior fue confirmado por integrantes de la mesa directiva, quienes mencionaron que la vestimenta ha experimentado bastantes cambios; las telas que se utilizaron en los inicios eran la manta y cabeza de indio, y los adornos consistían en diamantina y espejos. De forma similar se pasó de utilizar bambú, al empleo de canutillos de lámina galvanizada.

En la actualidad, el traje que visten está confeccionado con tela generalmente de poliéster en colores obscuros, y consiste comúnmente en un camisón largo y pantalones. A estos se les cosen canutillos de lámina que con el movimiento suenan — anteriormente se llegaron a utilizar corcholatas para producir sonido- y que en conjunto llegan a pesar entre seis y ocho kilogramos. Se confeccionan de distintas formas, de manera que pueden ser más pesados o livianos de acuerdo con el número de canutillos; es común que los trajes de los niños lleven menos canutillos para evitar que se fatiguen pronto, además de que están iniciándose en este arte. Con el tiempo podrán decidir cargar más peso dependiendo de sus posibilidades físicas y económicas.

Los integrantes de la mesa directiva mencionaron que existe celo entre las personas participantes por los diseños de los penachos y el vestuario, pues evitan copiarse y tratan de demostrar su mayor creatividad. Algunas prefieren representar símbolos prehispánicos en sus penachos, como Quetzalcóatl o los caballeros águila, otros prefieren animales o seres híbridos.

Así, la creatividad crece cada año ya que los grupos renuevan su vestimenta, especialmente los penachos. Esta actividad deben realizarla con antelación, ya que la elaboración de los trajes y de los "penachos" debe iniciar por lo menos seis meses antes de las festividades. En años recientes, comentó el señor Javier Guerrero, se tiende a volver a lo de antes, a diseños de Teotihuacán o de indios. Asimismo, entre las reglas que ha definido la mesa directiva se encuentra evitar que los penachos lleven calaveras o marcas que no correspondan con la "tradición" o que reflejen contradicciones con la fe católica (entrevista a Jaime Granados, Sahuayo, 2016).

\section{Coreografía}

Desde un punto de vista academicista se podría poner en tela de juicio si los Tlahualiles danzan o solo bailan al compás de cualquier música. En las entrevistas realizadas no fue posible definir si en algún momento hubo pasos establecidos, pero lo cierto es que, ante el mayor tamaño de los penachos, su vistosidad opacó los posibles trazos de piso en las coreografías. Javier Guerrero comentó que antes "se podía danzar", lo que se hacía de un lado a otro, porque el penacho era chico (entrevista, Sahuayo, 2016). Sin embargo, en la actualidad "en coreografía no hay nada, solo irse entrecruzando", cada integrante baila según quiera. Entre los pasos más vistosos y aplaudidos mencionó dar vueltas para demostrar al público cómo los danzantes se mantienen en equilibrio ante el peso que cargan. Solo el señor Martín González recordó que antes se bailaba "La culebra", en zigzag, y los danzantes se peleaban entre sí (entrevista a Martín González, Sahuayo, 2016). 
En cuanto a la música, Javier Guerrero afirmó que antes sí se ejecutaba una tonada especial que acompañaba al Tlahualil; en concreto, con la chirimía se tocaba "La culebrita", acompañada de un tambor. En cambio, Martín González recordó que antes la danza se acompañaba con música de banda, que tocaba la banda normal de ese tiempo. Hoy en día cada grupo se organiza y contrata una modalidad concreta de acompañamiento musical, que principalmente es música de banda.

\section{La reivindicación religiosa de la danza y el paganismo carnavalesco}

Los integrantes de la mesa directiva afirmaron estar preocupados por un llamado "paganismo" en la danza. Esto viene acompañado de un aumento en el número de grupos registrados, que pasaron de 35 en 1996, hasta contabilizarse aproximadamente 135 grupos en 2016, que sumaban entre 3000 y 5000 danzantes; ello desembocó en un nulo control de la fiesta, ya que asistían grupos vestidos "de cualquier cosa" que desconocían el "trasfondo religioso" de la veneración a Santiago, lo que generó desorden, "como en un carnaval".

Esta visión también fue registrada por Hernández y Canuto (2019), quienes a través de fuentes orales y fotográficas revisaron las continuidades y los cambios en la danza. Ellos mencionaron que el sentir de varios danzantes era que en la actualidad "tiene un aspecto de carnaval" por el ambiente de diversión exacerbada y los excesos que se cometían durante los principales días de la celebración.

Entre las historias locales recopiladas sobresalen las versiones atentas a la hagiografía del santo Santiago como uno de los doce apóstoles de Jesucristo, quien combatió contra los moros. Esto se trasladó al nuevo continente desde el siglo XVI, con el correlato de que Santiago se enfrentó a los Tlahualiles, quienes desde entonces se considerarían los guerreros vencidos, pero con una interpretación positiva dado que obtuvieron la fe verdadera. Así, la matanza simbólicamente es la "representación de que nos mata [Santiago]; ya cuando vuelves a levantarte, ya vienes ya renacido; o sea que ya sabes de la religión" (Hernández y Canuto, 2019, p. 7). Como apuntan Campos y Cardaillac (2007), la disputa entre moros y cristianos termina con el triunfo de los partidarios de la cruz, que se reivindican como auténticos detentores del bien, lo que en última instancia los convierte en auténticos seguidores de Cristo, y la consecuente conversión de los primeros.

Hernández y Canuto (2019) definen la danza de Tlahualiles como una danza de conquista, sin embargo, al ser tan abrumadora la participación de los Tlahualiles, se preguntan a quién está dedicada la fiesta de Sahuayo, si al santo Santiago o a los Tlahualiles. Precisamente en esta tensión significativa se pondera la organización emergente de la mesa directiva, que busca erradicar lo que sus integrantes refieren como "paganismo".

Durante el trabajo de campo realizado por quienes esto escriben, los miembros de la mesa directiva afirmaron que se danza por agradecimiento, aunque algunos grupos danzan también por tradición y por devoción. Afirmó Jaime Granados: "Es una emoción cuando uno va a salir y cuando va el santo" (entrevista, Sahuayo, 2016). Estos sentidos se enlazan con algunas motivaciones ya identificadas en la religiosidad popular. Sin embargo, Javier Guerrero consideraba como uno de los problemas de la danza que no todos los ejecutantes conocían los fundamentos, ya que a él la danza le venía de sus padres y por ello contaba con conocimientos, pero no todos los danzantes, refirió, conocían la historia de la representación (entrevista, Sahuayo, 2016). Rostas y Droogers mencionan que los adeptos de religiones populares se preocupan más por su eficiencia que por el origen de sus creencias y prácticas (Rostas y 
Droogers en De la Torre, 2013, p. 5), sin embargo tratan de incorporar o reinterpretar los orígenes para conferir legitimidad social y acercarse a la institución católica bajo sus términos (De la Torre, 2013).

Otra pista que sugiere la devoción popular es la existencia de relatos que aproximan al santo a la población y que lo hacen familiar. Pobladores de Sahuayo manifestaron la presencia de un Santiago niño que bajaba en su caballo durante las noches para vigilar las calles del pueblo. Con ello se ha trascendido la hagiografía del santo para desembocar en una religiosidad popular.

\section{La organización de la danza de Tlahualiles}

Román (1998) menciona que en la década de los ochenta del siglo XX se empezaron a organizar grupos de danza, y en 1988 se constituyó legalmente una agrupación, que en 1990 pasó a denominarse Organización de Tlahualiles Unidos. Desde entonces sus integrantes han tenido la intención de definir una estructura y normas para esta representación dancística. La mesa directiva de 2016 conformó reglas para los grupos de Tlahualiles, y formalizó la figura de jefe de danza. Los jefes de danza realizan juntas cada quince días para organizarse y discutir acerca de los asuntos que les atañen, como preparar los recorridos para las festividades, fortalecerse como asociación, asistir a invitaciones externas, etcétera; a estas reuniones acuden aproximadamente entre setenta y ochenta personas, y en ellas se firman acuerdos y se establecen sanciones para quienes no cumplan los reglamentos (comunicación oral, integrantes de la mesa directiva de Tlahualiles, Sahuayo, 2016).

Los grupos se conforman a partir de diferentes criterios. Pueden organizarse por barrios, por familias, o constituirse a partir de alguna diferencia o conflicto entre integrantes de una misma danza, de manera que deciden conformar un grupo propio. Algunos grupos tienen una larga tradición, mientras otros se han creado hace pocos años.

El jefe de danza es el responsable, es quien coordina y organiza la confección de los trajes y penachos, propone al grupo algún diseño y se encarga de que durante el recorrido, en los días de fiesta, todos los integrantes tengan un desempeño adecuado, es decir, que dancen y sigan las reglas establecidas por la mesa directiva. Uno de los jefes de danza comentó: "es muy duro, hay que controlarlos porque hay mucha bebida en la fiesta". En ocasiones, afirman integrantes de la mesa directiva, se puede negar la entrada a alguna persona porque se sabe que es conflictiva, y en otros casos los integrantes se retiran porque no les gusta el traje, el penacho o la disciplina. Además, comentaron que en el interior de los grupos suelen existir conflictos que el jefe de danza tiene que resolver, por lo que debe ser una persona con liderazgo: "uno de encargado tiene que tener la batuta" (comunicación oral, integrantes de la mesa directiva de Tlahualiles, Sahuayo, 2016).

Esta organización no se parece a la de las mayordomías que existen en algunas poblaciones indígenas, pero es importante reconocer que se trata de un sistema que surge de la comunidad y que coordina esfuerzos colectivos; la dirigencia de esta organización se nombra a sí misma "mesa directiva". Como una clave de la religiosidad popular, esta figura visible parece funcionar como intermediaria entre el sistema eclesial, las familias y los grupos de la comunidad; su funcionamiento implica "redes de apoyo, alianzas y rupturas entre familias, estrategias económicas aplicadas durante todo el año y la participación (o no participación) de las familias de la comunidad” (Gómez A., 2009, p. 26).

Los miembros de la mesa directiva mencionaron que antes "ni sabíamos el significado de la danza", en este sentido, han trabajado para que los grupos la conozcan y valoren. Asimismo, se han acercado a la Iglesia católica para crear un vínculo directo entre las danzas y la devoción a los santos de la localidad. 
Afirmaron que antes había "mucho paganismo" y que en la actualidad existe hasta una catequesis de los danzantes. Anteriormente era común que junto con esta danza salieran los "disfrazados" - los pachucos, los panaderos, los negros, un gorila, un político o un payasito-, pero se ha tratado de "ir quitando lo carnavalesco", que no tiene relación con Santiago. Estas expresiones pueden indicar la adopción del discurso hegemónico elaborado por la Iglesia católica, pero también pueden sugerir que los danzantes están dispuestos a construir sus propias interpretaciones de estos discursos.

\section{La intervención de las instituciones en la danza}

Los miembros de la mesa directiva afirmaron que, según su registro y lo que cuentan las personas mayores, la danza tiene una antigüedad de aproximadamente cien años. Los grupos más antiguos son Los Guerrero y Los Granados, pero hace aproximadamente diecinueve años el municipio organizó un concurso de danzas y de vestuario - penachos_- para fomentar el aprecio por la expresión y la creatividad de los danzantes. Sin embargo este concurso, afirman, causó conflictos entre los ejecutantes al no existir reglas claras y al valorarse de distinta forma los vestuarios de los concursantes: el ayuntamiento "creó un conflicto entre los grupos", aseveraron.

Además, esto también generó competencia entre ellos y ambición por hacer los penachos más grandes, y con más adornos o elementos. Lo anterior ocasionó que algunos grupos se desintegraran, por lo que el número de danzantes disminuyó. Ante estos hechos se ha evitado hacer nuevos concursos y se procura simplemente ejecutar los recorridos como se ha hecho por generaciones, postura que da cuenta de prácticas como la solidaridad y la cohesión entre los grupos de danza.

La tensión entre fiesta profana y veneración religiosa es la tónica fundamental del trabajo de la mesa directiva a fin de establecer reglas para todos los grupos de danzantes, ya que estas expresiones se han asociado con excesos y desenfreno. Así se han establecido reglas como no ingerir bebidas alcohólicas durante los recorridos, respetar el turno de cada grupo y no excederse en vueltas o coreografías que pongan en riesgo la salud de los danzantes. De esta forma se ha tratado de sacralizar la danza y de mostrar su lado ritual como una ofrenda a los santos y deidades del lugar. Uno de los integrantes afirmó: "No es un carnaval, es una fiesta religiosa".

Hace aproximadamente quince años, afirman los miembros de la mesa directiva, un sacerdote estuvo comprometido con la fiesta del santuario y se acercó a los grupos para conocer la danza. Estas acciones posiblemente se relacionan con la "nueva evangelización", promovida por la Iglesia católica en la década de los noventa del siglo XX, que tuvo como fin valorar las Iglesias locales e "inculcar el evangelio", lo que igualmente evidencia la diversidad de estrategias de este actor hegemónico para hacerse presente y renovar su sentido entre el grueso de la población (Báez-Jorge, 2009). Finalmente, esto contribuyó a la actual cercanía que mencionan los danzantes con la Iglesia católica del lugar.

En cuanto al papel del ayuntamiento como promotor de la tradición, se reduce a las imágenes que promueven al municipio; los integrantes de la mesa directiva afirman que reciben poco apoyo del gobierno local, que en ocasiones les proporciona playeras y a veces ni eso. Comentaron: "Los ayuntamientos no han sabido valorar a los Tlahualiles". Desde su apreciación, esta actividad genera bastantes empleos: los vendedores de las materias primas para los trajes y penachos, las personas que los confeccionan y los comerciantes que se benefician con la asistencia de personas de otras localidades durante los días festivos. Afirman que la derrama económica ha aumentado ante el interés que causa la danza. En esta 
línea, la religiosidad popular puede evidenciar relaciones de poder (entre autoridades locales y la mesa directiva), negociaciones (con la Iglesia católica) y tensiones en la comunidad (entre grupos de danzantes).

Por lo anterior, se ha pensado en crear un museo de Tlahualiles, ya que consideran que la danza es conocida fuera de la región, en otros municipios y estados, como Jalisco. Incluso mencionaron que habían hecho representaciones en Estados Unidos, específicamente en localidades donde residen sahuayenses que han migrado y que se han interesado por preservar y dar a conocer esta costumbre.

\section{Reflexiones finales}

Con este texto nos hemos propuesto presentar una posible interpretación de la danza y contrastarla con su versión más actual. Las tensiones manifiestas entre la fe católica y su enemigo, la idolatría, se conservan hasta el día de hoy, pero la marca de una fiesta religiosa profana - como parece enunciarse en sus inicios- está siendo cuestionada por los mismos actores. En este sentido, damos cuenta de un proceso de "consagración" de la danza para quitarle "el paganismo", como refieren los mismos danzantes, y lograr que se sustente en la fe católica como emblema del ofrecimiento al santo patrono del lugar.

Es posible que a partir de la danza de Tlahualiles, y lo que ello implica para el ciclo de vida en Sahuayo, se experimenten procesos de redefinición y reinterpretación del sentido práctico de la religión (Dela Torre, 2013) al recurrir al orden dogmático eclesial, pero sin subordinarse a este. Desde las discusiones de la religiosidad popular, esta mantiene una lógica propia que responde a necesidades concretas de la comunidad (Gómez A., 2009), lo que en última instancia genera una tensión continua con la Iglesia católica, que al igual que la religiosidad popular elabora estrategias para redefinir su sentido. A pesar de estas tensiones, se evidenció un acercamiento entre estas instancias y la necesidad de los danzantes de justificar su práctica ritual "en la continuidad y el sentido popular", pues en estos espacios reelaboran su eficacia simbólica (De la Torre, 2013, p. 19).

A partir de las fuentes documentales nos preguntamos: ¿en algún momento se pensó en que Santiago Matamoros fuera Tlacatecolotl, y los Tlahualiles su advocación enfurecida, siendo parte del mismo complejo dual prehispánico? Si bien en el trabajo de campo no encontramos referencias directas a esta asociación, es posible que el Tlahualil, al identificarse como un demonio, loco y desenfrenado, no sea bien visto por los promotores oficiales de estos grupos de danza (comunicación oral, integrantes de la mesa directiva de Tlahualiles, Sahuayo, 2016). En tal sentido, parece más conveniente la asociación de los Tlahualiles con los moros - pintados con tizne para aparentar el color negro de la piel de los esclavos-. En este escenario una danza que ha tenido diferentes cambios experimenta un proceso de resignificación que tiene como finalidad reivindicar una tradición en vínculo directo con lo sagrado para legitimarse.

En la línea de la religiosidad popular, la fiesta en honor a Santiago: "Cumple con la función de reproducción y fortalecimiento cultural e identitario [...] estas prácticas pagano-religiosas permiten la reconstrucción simbólica de la comunidad" (Landázuri, 2012, p. II). Es entonces un espacio propicio para que los danzantes de Tlahualil instituyan nuevos sentidos culturales, como comenta De la Torre (2013), al marcar una diferencia con lo "pagano" y desencadenar nuevos significados reinterpretados por los mismos danzantes.

Con estas líneas también queremos llamar la atención sobre una práctica festiva que ha logrado ser considerada como símbolo de una ciudad, y que en este proceso ha conformado una identidad entre las familias y grupos que danzan. Lo anterior da cuenta de la importancia que ha ido adquiriendo la danza de Tlahualiles y todos los aspectos que se relacionan con su práctica. Si bien sería necesario un estudio más profundo en distintos sentidos - histórico, antropológico, lingüístico-, pensamos que con estas apreciaciones se puede abrir una línea interpretativa de esta y otras prácticas culturales asociadas con la danza de Tlahualiles. 


\section{Referencias}

Báez-Jorge, F. (1996). Los hijos de Guadalupe: religiosidad popular y pluralidad cultural en México. En NOSTRA AMERICA. RAZZA COSMICA (pp. 5-30). Ricerche Giuridiche e Politiche Rendiconti, X.

Báez-Jorge, F. (2009). "Nueva evangelización" y religiosidad popular indígena (Estrategias de una teología hegemónica). En J. Broda (coord.), Religiosidad populary Cosmovisiones indígenas en la historia de México (pp. 147160). Instituto Nacional de Antropología e Historia.

Báez-Jorge, F., y Gómez Martínez, A. (1998). Tlacatecolotl y el diablo. (La cosmovisión de los nahuas de Chicontepec). Gobierno de Veracruz.

Bonfiglioli, C., y Jáuregui, J. (1996). Introducción: el complejo dancístico-teatral de la conquista. En J. Jáuregui y C. Bonfigliolo (coords.), Las danzas de conquista I. México contemporáneo (pp. 7-30). Fondo de Cultura Económica; Consejo Nacional para la Cultura y las Artes.

Campos, A., y Cardaillac, L. (2007). Indios y cristianos. Cómo en México el Santiago español se hizo indio. El Colegio de Jalisco; Universidad Nacional Autónoma de México; Editorial Ítaca.

Croda León, R. (2009). Una mirada a los carnavales indígenas del norte de Veracruz. En L. Báez Cubero y M. G. Garrett Ríos (coords.), Los rostros de la alteridad. Expresiones carnavalescas en la ritualidad indígena (pp. 149164). Consejo Veracruzano de Arte Popular.

Dela Torre, R. (2013). La religiosidad popular. Encrucijada de las nuevas formas de la religiosidad contemporánea y la tradición (el caso de México). Ponto Urbe. Revista do Núcleo de Antropologia Urbana da USP, 12. https://doi. org/10.4000/pontourbe.581

Echeverría García, J. (2005). Los conceptos de locura entre los antiguos nahuas. Diario de Campo, 76, 57-62.

Gómez Arzápalo, Ramiro (2009). Utilidad teórica de un término problemático: la religiosidad popular. En J. Broda (coord.), Religiosidad popular y cosmovisiones indígenas en la historia de México (pp. 21-33). Instituto Nacional de Antropología e Historia.

Gómez Arzapalo, R. A. (2019). La religiosidad popular en México. Política y Cultura, 52, 227-232. https:/polcul. xoc.uam.mx/index.php/polcul/article/view/1401

Gómez Martínez, A. (2009). Tlacatecolotl y Tzizimitl como tutelares del carnaval. En L. Báez Cubero y M. G. Garrett Ríos (coords.), Los rostros de la alteridad. Expresiones carnavalescas en la ritualidad indígena (pp. 271-293). Consejo Veracruzano de Arte Popular.

González González, M. (2009). El rastro del otro: carnaval como deixis nahua, el caso de Xochiatipan, Hidalgo. En L. Báez Cubero y M. G. Garrett Ríos (coords.), Los rostros de la alteridad. Expresiones carnavalescas en la ritualidad indígena (pp. 231-269). Consejo Veracruzano de Arte Popular.

Hernández Vaca, V., y Canuto Castillo, F. (2019). Tradición y sentido en la danza de los Tlahualiles en la festividad de santo Santiago en Sahuayo, Michoacán. Acta Universitaria, 29, 1-19. https://doi.org/10.15174/ au.2019.2109

Instituto Nacional para el Federalismo y el Desarrollo Municipal (INAFED) (ca. 2013). Tlahualilo. Enciclopedia de los municipios y delegaciones de México. http://www.inafed.gob.mx/work/enciclopedia/EMMlodurango/ municipios/10036a.html

Instituto Nacional para el Federalismo y el Desarrollo Municipal (INAFED) (2017). Sahuayo. En Enciclopedia de los municipios y delegaciones de México. http://siglo.inafed.gob.mx/enciclopedia/EMMl6michoacan/ municipios/16076a.html

Landázuri Benítez, G. (2012). Signos y símbolos de la religiosidad popular. Política y Cultura, 38, I-XVI. http:// www.scielo.org.mx/scielo.php?script=sci_arttext\&epid=S0188-77422012000200009\& \&lng=es\&tlng=es

León Portilla, M. (1997). La filosofía náhuatl estudiada en sus fuentes. Universidad Nacional Autónoma de México.

Martínez Yépez, H. (2018). ¿Sueñan los marxistas con revoluciones aztecas? Poéticas del náhuatl y el México de Karl Marx y Walter Benjamin [tesis de doctorado en Filosofía, Universidad de California].

Molina, A. de (1571). Vocabulario en lengua castellana y mexicana. Casa de Antonio Espinosa. http://alfama.sim.ucm. es/dioscorides/consulta_libro.asp?ref=B23658927\&\&idioma=0

Montemayor, C. (2017). Diccionario del náhuatlenel español de México. Nueva edición corregida y aumentada. Universidad Nacional Autónoma de México.

Municipios.mx (s. f.). Sahuayo. http://www.municipios.mx/michoacan/sahuayo/

Pedrosa, J. M. (2013). Prólogo. Santiago en México: el santo de las mil caras. En A. Campos M., Lo que de Santiago se sigue contando. Leyendas del apóstol Santiago en México (pp. 15-33). El Colegio de Jalisco.

Román Garza, J. T. (1998). De Jacobo a Santiago. De Cafarnaúm a Sahuayo. Amate.

Sahagún, B. de (1830). Historia general de las cosas de Nueva España, t. III, libro X. Imprenta de Alejandro Valdés.

Siméon, R. (2014). Diccionario de la lengua náhuatl o mexicana. Siglo XXI Editores. 


\section{Referencias}

Arribas, A. (2018). Intranet para la gestión del conocimiento y la comunicación interna. Razón y Palabra, 22(1100), 406-413. https://www.revistarazonypalabra.com/index.php/ryp/article/view/1163

Capriotti, P. (1999). Planificación estratégica de la imagen corporativa. Ariel.

Dörnyei, Z. (2007). Research methods in applied linguistics: Quantitative, qualitative, and mixed methodologies. Oxford University Press.

Fernández, M., y Savall, H. (2004). El modelo de gestión socio-económica en organizaciones mexicanas. Universidad Autónoma Metropolitana-Iztapalapa.

Fuentes, O. (2015). La organización escolar. Fundamentos e importancia para la dirección en la educación. VARONA, Revista Cientifico-Metodológica, (61), 1-12. https://www.redalyc.org/pdf/3606/360643422005.pdf

Fundación SERES (2014, 6 de noviembre). 10 consejos para comunicar con éxito la RSE. Compromiso RSE. https:/www.compromisorse.com/rse/2014/11/06/10-consejos-para-comunicar-con-exito-la-rse-/

Garbanzo-Vargas, G. (2016). Desarrollo organizacional y los procesos de cambio en las instituciones educativas, un reto de la gestión de la educación. Revista Educación. 40(1), 67-87. http://dx.doi.org/10.15517/revedu.v40il.22534

Hernández Flores, H. G. (2018). De la comunicación institucional a la responsable, un beneficio auténtico para las organizaciones. ObservaRSE. http://www.observarse.com/2018/01/04/comunicacion-institucionalresponsable-beneficio-organizaciones/

Instituto de Socioeconomía de las Empresas y Organizaciones (ISEOR) (s.f.). El modelo de gestión socioeconómica en organizaciones mexicanas. http://164.132.163.82/SiteIseor/ouvrages_fiche.asp?code=LIV2004MFE001

Jaksa, J. (1996). Responsible Communication: Ethical Issues in Business, Industry, and the Professions. Hampton Press.

Meseguer, J., García, M., y Hernández, R. (2018). Manual de comunicación creativa y responsable. Universidad Católica San Antonio, Lógica Ecommerce. https:/logicaecommerce.com/formacion/wp-content/ uploads/2018/12/guia-de-la-comunicacion-responsable-final.pdf

Orozco-Toro, J., y Ferré-Pavia, C. (2019). Los intangibles de la marca y su efecto en la reputación corporativa. La evaluación de toda cadena de valor de Televisión de Catalunya. Revista de Comunicación, 18(1), 111-134. https://doi.org/10.26441/RC18.1-2019-A6

Oyarvide-Ramírez, H., Reyes-Sarria, E., y Montaño-Colorado, M. (2017). La comunicación interna como herramienta indispensable de la administración de empresas. Revista Científica Dominio de las Ciencias, 3(4), 296-309. http://dx.doi.org/10.23857/dc.v3i4.687

Paladines, F., Valarezo, K., y Yaguache, J. (2013). La comunicación integral, un factor determinante en la gestión de la empresa ecuatoriana. Signo y Pensamiento, 32(63), 110-128. https://doi.org/10.11144/Javeriana.syp32-63.cifd

Pertúz, F. (2018). Liderazgo transformacional en empresas sociales desde la perspectiva ética de la responsabilidad social empresarial. Telos, 20(2), 377-388. https://dialnet.unirioja.es/servlet/articulo?codigo=6436416

Ramírez, R., y Hugueth, A. (2017). Modelo de comunicación productiva para las organizaciones de salud pública en Venezuela. Opción, 33(83), 305-335. https://www.redalyc.org/pdf/310/31053772011.pdf

Remund, D. L. (2015). The ART of Responsible Communication: Leading with Values Every Day. Business Expert.

Rincón, Y., y Ramírez, R. (2018). Comunicación responsable en las organizaciones. En Quintero, M., y Sánchez, M. (eds.). Responsabilidad social corporativa. Una mirada integral en América Latina (pp. 93-100). Editorial Univalle. https://www.researchgate.net/publication/328160423_Comunicacion_responsable_en_las_organizaciones

Rincón, Y., Sukier, H., Contreras, J., y Ramírez, R. (2019). Estrategias de comunicación responsable para pequeñas y medianas empresas. Opción, 35(89-2), 1208-1234. https://repositorio.cuc.edu.co/ handle/11323/5377

Rivera Salas, P., y Hernández Flores, H. (2020). Comunicación responsable en infografías digitales publicadas por empresas farmacéuticas. Correspondencias e Análisis, (12). https://doi.org/10.24265/cian.2020.nl2.02

Rodríguez-Cruz, Y., y Pinto, M. (2018). Modelo de uso de información para la toma de decisiones estratégicas en organizaciones de información. Transinformação, 30(1), 51-64. https://doi.org/10.1590/231808892018000100005

Tapia-Carreto, A., Mendoza, R., y Martínez, O. (2016). Reconociendo el desarrollo de competencias sociodiscursivas en la universidad. Ágora de Heterodixias, 2(2), 22-36. https://redib.org/Record/oai_articulo2905109reconociendo-el-desarrollo-de-competencias-socio-discursivas-en-la-universidad

Vásquez-Rizo, F.-E., y Gabalán-Coello, J. (2015). Información y ventaja competitiva. Coexistencia exitosa en las organizaciones de vanguardia. Profesional de la Información, 24(2), 149-156. https://doi.org/10.3145/epi.2015.mar.08

Villalba, J. (2015, 9 de marzo). Comunicación responsable: una oportunidad para ganar. Telefónica Empresas. https://empresas.blogthinkbig.com/comunicacion-responsable-una-oportunidad-para-ganar/ 